\title{
Melatonin Contributes to The Hypertrophic Differentiation of Mesenchymal Stem Cell-Derived Chondrocytes Via Activation of The WNT/ $\beta$-Catenin Signaling Pathway
}

\section{Xuan Wang}

Third Affiliated Hospital of Sun Yat-Sen University

Tianwei He

Third Affiliated Hospital of Sun Yat-Sen University

Lei He

Third Affiliated Hospital of Sun Yat-Sen University

\section{Bu Yang}

Third Affiliated Hospital of Sun Yat-Sen University

\section{Zhongyu Liu}

Third Affiliated Hospital of Sun Yat-Sen University

\section{Mao Pang}

Third Affiliated Hospital of Sun Yat-Sen University

\section{Peigen Xie}

Third Affiliated Hospital of Sun Yat-Sen University

\section{Liangming Zhang}

Third Affiliated Hospital of Sun Yat-Sen University

\section{Limin Rong ( $D$ ronglm@mail.sysu.edu.cn )}

Third Affiliated Hospital of Sun Yat-Sen University

\section{Research}

Keywords: melatonin, mesenchymal stem cells, chondrocyte hypertrophy, WNT/ $\beta$-catenin signaling pathway

Posted Date: May 4th, 2021

DOl: https://doi.org/10.21203/rs.3.rs-448728/v1

License: (9) (1) This work is licensed under a Creative Commons Attribution 4.0 International License. Read Full License 
Version of Record: A version of this preprint was published at Stem Cell Research \& Therapy on August 21st, 2021. See the published version at https://doi.org/10.1186/s13287-021-02536-x. 


\section{Abstract}

\section{Background}

Hypertrophy is a critical process for chondrocyte differentiation and maturation during endochondral ossification, which is responsible for the formation of long bone and its postnatal longitudinal growth. Increasing evidence suggests that melatonin, an indole hormone, plays a pivotal role in chondrogenesis; however, little is known about its effects on the terminal differentiation of chondrocytes.

\section{Methods}

Mesenchymal stem cells (MSCs) derived chondrocytes generated by a high-density micromass culture system were further induced to hypertrophic differentiation. The melatonin-mediated hypertrophic differentiation were examined by reverse transcription polymerase chain reaction analysis (RT-PCR) analysis and histological staining and immunohistochemistry. The expression of downstream factors of WNT signaling pathway was evaluated by RT-PCR, western blotting and immunofluorescence. The WNT signaling pathway antagonist XAV-939 was used to further demonstrate melatonin-induced hypertrophic chondrocytes and WNT signaling pathway activation.

\section{Results}

Histological staining showed melatonin increased the chondrocytes cell volume and the expression of type X collagen, but decreased the expression of type II collagen compare to the control group. RT-PCR showed that melatonin significantly up-regulated the expression of biomarkers of hypertrophic chondrocytes, including type $X$ collagen (COL10A1), alkaline phosphatase (ALP), Runt-related transcription factor 2 (RUNX2), Indian hedgehog $(\mathrm{IHH})$, and parathyroid hormone-related protein receptor (PTHrP-R) and down-regulated the hallmarks of chondrocytes, including parathyroid hormone-related protein (PTHrP). The WNT signaling pathway PCR array showed that the effect of melatonin was accompanied by the up-regulation of multiple target genes of the canonical WNT signaling pathway and the melatonin-mediated effect can be blocked by XAV-939.

\section{Conclusions}

These findings demonstrate that melatonin can enhance the hypertrophic differentiation of MSCs-derived chondrocytes through the WNT signaling pathway. It adds evidence to the role of melatonin in promoting bone development and highlights its positive effects on chondrocytes terminal differentiation.

\section{Introduction}

Endochondral ossification (EO), one of the main processes of skeletal development in vertebrates, is characterized by bony tissues progressively replacing cartilaginous tissues for normal bone architecture formation [1, 2]. Mesenchymal stem cells (MSCs), the progenitors of chondrocytes, undergo a series of steps including proliferation, pre-hypertrophy, and hypertrophy in the process of EO for cell maturation 
and skeletal morphogenesis, which is perfectly demonstrated by the growth plate, an organized cartilaginous structure in the metaphysis [3]. The growth plate is subdivided into three structurally and functionally independent zones: the resting zone, containing round chondrocytes, the proliferative zone, containing flattened chondrocytes, and the hypertrophic zone, containing enlarged chondrocytes; these zones are spatially located from both ends to the middle along the vertical axis of the long bone[4, 5]. The hypertrophic zone is considered to serve as a signal-transducing center, in which several cell signaling pathways are involved in cross-talk for the regulation precision of chondrocyte hypertrophic differentiation [5]. Chondrocyte hypertrophy contributes more substantially to bone growth rate than chondrocyte proliferation through cell volume enlargement [6, 7]. Moreover, hypertrophic chondrocytes act as "intermediators" in the turnover of cartilage to bone. Therefore, an increasing number of investigations highlight chondrocyte hypertrophic differentiation as the pivotal stage in EO.

Hypertrophy, an irreversible stage of chondrocyte terminal differentiation, is controlled by many signaling pathways including the WNT/ $\beta$-catenin signaling pathway [8-10]. The canonical WNT/ $\beta$-catenin pathway orchestrates chondrocyte hypertrophy by the translocation of $\beta$-catenin into the nucleus and the binding of $\beta$-catenin with the T cell-specific factor (TCF) or lymphoid enhancer binding protein (LEF) [11], leading to activation of the hypertrophy related gene RUNX2 in the nucleus [12]. However, the concrete molecular framework for chondrocyte hypertrophy remains unclear.

Melatonin, an amine hormone, is mainly secreted by the pineal gland of mammals, especially in dark environments. Melatonin participates in biological events via membrane receptors and nuclear receptors and is involved in the regulation of many pathophysiological processes [13] such as clock rhythm [14, $15]$, immune response $[16,17]$, cellular senescence $[18,19]$, and bone development $[20,21]$.

An increasing number of studies show that melatonin participates in chondrocyte differentiation and maintenance. Pei et al. reported that melatonin can enhance the synthesis of matrix in porcine joint chondrocytes [22]. Zhong ZM et al. suggested that at higher concentrations, melatonin can inhibit the proliferation and differentiation of chondrocytes from the growth plate of the vertebral body in rats [23]. Our previous data showed that melatonin can promote the differentiation of MSCs into chondrocytes at low concentrations [24]. While it has been proven that melatonin participates in and regulates chondrocyte differentiation, its effect on the hypertrophic differentiation of chondrocytes, which is the terminal stage of chondrocyte differentiation, needs to be studied further. The present study evaluated the effect of melatonin on human bone marrow mesenchymal stem cells (BMSCs) and C3H10T1/2-derived chondrocytes and further analyzed the effect of melatonin on EO, providing insights into understanding skeletal development and the potential use of melatonin as a therapeutic drug for cartilage disorders and cartilage development-related diseases.

\section{Materials And Methods}

\section{Cell culture}


This study was approved by the ethics committee of Sun Yat-Sen University and informed consent was obtained from all the individuals included in this study. Bone marrow samples were obtained from five human volunteers (mean age: 25 years, range: 18-30 years). MSCs were cultured by the whole bone marrow culture method [25]. C3H10T1/2 cells were bought from the cell bank of the Chinese Academy of Science, Shang Hai. Two kinds of cells were separately attached in $25 \mathrm{~cm}^{2}$ flasks, which were filled with 5 $\mathrm{ml}$ of growth medium, including the low-glucose Dulbecco's modified Eagle's medium (DMEM) with 10\% fetal bovine serum(FBS), incubated at $37{ }^{\circ} \mathrm{C}$ with $5 \% \mathrm{CO}_{2}$. The growth medium was changed every three days and the cells were digested with trypsin at $80 \%$ confluence, then counted, and plated again. After monolayer expansion, cells from passage 3-6 were selected for the experiments.

\section{Chondrogenic and hypertrophic differentiation}

A high-density micromass culture system was used for the chondrogenic differentiation of MSCs and C3H10T1/2 cells as described previously $[24,25]$. The cells were briefly trypsinized, washed with PBS, and then resuspended at a concentration of $2 \otimes 10^{7}$ cells $/ \mathrm{mL}$ in a chemically defined chondrogenic medium consisting of high-glucose DMEM supplemented with $10 \mathrm{ng} / \mathrm{mL}$ recombinant human transforming growth factor- $\beta 3$ (TGF- $\beta 3$; Peprotech, USA), 100 nM dexamethasone (Sigma, USA), 50 $\mu \mathrm{g} / \mathrm{mL}$ ascorbic acid 2-phosphate (Sigma, USA), $1 \mathrm{mM}$ sodium pyruvate (Sigma, USA), $40 \mu \mathrm{g} / \mathrm{mL}$ proline (Sigma, USA), and ITS + Universal Culture Supplement Premix (Corning, USA; final concentrations: 6.25 $\mu \mathrm{g} / \mathrm{mL}$ bovine insulin, $6.25 \mu \mathrm{g} / \mathrm{mL}$ transferrin, $6.25 \mu \mathrm{g} / \mathrm{mL}$ selenous acid, $5.33 \mu \mathrm{g} / \mathrm{mL}$ linoleic acid, and $1.25 \mathrm{mg} / \mathrm{mL}$ bovine serum albumin). Droplets $(15 \mu \mathrm{L})$ were carefully placed in each well of a 24 -well plate. Cells were allowed to assemble at $37^{\circ} \mathrm{C}$ in an incubator for 2 hours, after which $500 \mu \mathrm{L}$ of chondrogenic medium was added along the well's wall slowly. The cell clusters were exposed to chondrogenic medium for two weeks, and the medium was changed every other day. Then, the culture environment was changed to a hypertrophic enhancing medium by the following steps: the withdrawal of TGF- $\beta$ from the chondrogenic medium, addition of $1 \mathrm{nM}$ triiodothyronine (T3) (Sigma), reduction in the level of dexamethasone to $1 \mathrm{nM}$, and addition of vehicle or $100 \mathrm{nM}$ melatonin (Sigma). The induced hypertrophic cartilage tissues were harvested 1-3 weeks later. For blocking the WNT/ $\beta$-catenin signaling pathway, the $\beta$-catenin antagonist XAV-939 (10 $\mu \mathrm{M})$ (Selleckchem, USA) was used.

\section{Reverse transcription and real-time polymerase chain reaction (RT-PCR) analysis}

Total RNA was isolated from the aggregates using the total RNA Kit (Omega Bio-Tec, USA), following the manufacturer's protocol. The total RNA (500 ng) was then converted to cDNA. All real-time quantitative polymerase chain reactions (PCRs) were performed on a Roche 480 Real-Time PCR Detection System (Roche Diagnostics) in $20 \mu \mathrm{L}$ reaction volumes containing $10 \mu \mathrm{L}$ of SYBR Green I Master Mix (Roche Diagnostics), $2 \mu \mathrm{L}$ of $10 \mathrm{mM}$ sense or antisense primer, and $6 \mu \mathrm{L}$ of RNAse-free water. The expressions of the following genes were examined: COLX, RUNX2, ALP,IHH, and PTHrP-R and PTHrP. Glyceraldehyde-3phosphate dehydrogenase (GAPDH) was used as a housekeeping gene. The PCR was performed for 1 min at $95^{\circ} \mathrm{C}$, followed by 39 amplification cycles $\left(15 \mathrm{~s}\right.$ at $95^{\circ} \mathrm{C}, 15 \mathrm{~s}$ at $60^{\circ} \mathrm{C}$, and $20 \mathrm{~s}$ at $\left.72{ }^{\circ} \mathrm{C}\right)$. After 
the last cycle, a melt-curve was generated. The $\mathrm{Ct}$ value of GAPDH was subtracted from the $\mathrm{Ct}$ value of the interest gene $(\triangle \mathrm{Ct})$. The average $\triangle \mathrm{Ct}$ value of the triplicates was taken. MSCs cultured in the pellet culture system were used as controls $(\triangle \triangle \mathrm{Ct})$. Relative expression levels for each primer set were expressed as fold changes by the $2^{-\triangle \Delta \mathrm{Ct}}$ method.

\section{Western blotting}

Cell and tissue lysates were lysed using RIPA lysis buffer (Beyotime, China) with the addition of Halt ${ }^{\text {tM }}$ Protease and phosphatase inhibitor cocktail (Thermo, USA). Electrophoresis was performed with $8 \%$ SDSPAGE gels and transferred onto PVDF membranes (Millipore, USA). The membranes were blocked with $5 \%$ no-fat milk; the primary antibodies and secondary antibodies were used according to the manufacturer's instructions. Western band images were digitally captured by an automatic chemiluminescence system (Tanon, China), and the intensity of the bands (pixels/band) was determined using ImageJ densitometry analysis software in arbitrary optical density units.

\section{Histology and immunohistochemistry}

The cartilage aggregates were fixed in $10 \%$ formaldehyde solution for 24 hours, then dehydrated with an ethanol gradient, and embedded in paraffin. The paraffin blocks were cut by a pathologic microtome section processor at a section thickness of 3-5 $\mu \mathrm{m}$, and then, the sections were coated on to glass slides carefully. Toluidine blue staining was used to assess the proteoglycan level, and immunohistochemistry was performed to assess the levels of collagen type II, collagen type X. Hematoxylin served as a counterstain for the nucleus. Briefly, for toluidine blue staining, the sections were dewaxed with xylene and rehydrated with an alcohol gradient; next, the sections were exposed to toluidine blue solution for 15 min and then immersed in acetone for $3 \mathrm{~min}$. For immunohistochemistry, the Histostain-Plus kit (ZSGBBIO, Beijing, China) was used. After dewaxing and rehydration, tissue sections were treated with pepsin at $37^{\circ} \mathrm{C}$ for $10 \mathrm{~min}$, incubated with peroxidase-blocking solution for $10 \mathrm{~min}$, blocked with $5 \%$ bovine serum albumin for $30 \mathrm{~min}$ at room temperature, and then allowed to react with the appropriate primary antibodies overnight at $4^{\circ} \mathrm{C}$. Mouse anti-human Col-X monoclonal antibodies (Abcam, USA) were diluted at 1:2000, rabbit anti-human Col-II polyclonal antibodies (Abzoom Biolabs, USA) were diluted at 1:500. Detection was conducted with a DAB Horseradish Peroxidase Color Development Kit (ZSGB-BIO, Beijing, China) according to the manufacturer's protocol. After dehydration in alcohol and clearance in xylene, the sections were mounted. Finally, the sections were photographed with a microscope (Leica, Germany).

\section{Immunofluorescence}

The cells were washed with PBS twice and fixed in 4\% paraformaldehyde at room temperature for 15 min. Next, the fixed cells were washed with PBS twice and incubated with specific primary antibodies and species-matched secondary antibodies labeled with Alexa Fluor 488, (Life science, USA, diluted at 1:500 in $1 \%$ BSA) according to each manual. The nuclei were labeled with Hoechst 33342 (Beyotime Biotechnology, Beijing, China).

\section{Statistical analysis}


All experiments were performed at least three times. Statistical analysis was performed using one-way ANOVA followed by a t-test with the SPSS version 20.0 software. Values of $P<0.05$ were considered statistically significant.

\section{Results}

\section{Melatonin leads to the hypertrophic differentiation of MSC- derived chondrocytes}

It is known that hypertrophy, due to the enlargement of component cells, contributes to an increase in the volume of an organ or tissue; thus, both the volume and weight of the hypertrophic chondrocyte were examined in this study. After inducing hypertrophy for 1 week and 3 weeks, the melatonin-treated chondrocytes aggregates were found to be much larger in size than those in the control group (Fig. 1A). The aggregates were globoids and their volumes were calculated by measuring their diameters. The dry weight was measured with a precision electronic scale. The statistical analysis of both the volumes and weights of the aggregates indicated the positive effect of melatonin on the hypertrophic differentiation of BMSC-derived chondrocytes (Fig. 1D and 1E). Staining with Alcian blue and toluidine blue was done for the precision display of single chondrocytes, which were found to be much larger in size (Fig. 1B and 1C). The statistical analyses of chondrocyte diameter and volume are shown in Fig. 1F and 1G.

\section{Melatonin promotes hypertrophic gene expression in the chondrogenesis of BMSCs and C3H10T1/2 cells}

Chondrocyte hypertrophy is characterized by the up-regulation of COL10A1, IHH, PTHrP-R, RUNX2, and ALP and the down-regulation of PTHrP. The mRNA expression of these genes was examined at different time points (Fig. 2A-2F). The expression of all genes except PTHrP were enhanced when melatonin was present, and similar results were observed in $\mathrm{C} 3 \mathrm{H} 10 \mathrm{~T} 1 / 2$ cell chondrogenesis (Fig. 2G-2J). Collagen remodeling, assuming that type II collagen (Col-II) level decreases and type $\mathrm{X}$ collagen (Col-X) level increases, was the most characteristic change in hypertrophic differentiation. Immunohistochemistry showed that level was decreased Col-II and Col-X level was elevated when melatonin was added (Fig. 3A and 3D) and integral optical density (IOD) analysis was calculated and is presented in Figs. 3B, 3C, 3E, and $3 \mathrm{~F}$, also demonstrating the positive effect of melatonin on BMSC-derived chondrocyte hypertrophic differentiation.

\section{Melatonin membrane receptor inhibitor blocks melatonin- mediated hypertrophic differentiation}

To investigate whether the effect of melatonin on chondrocyte hypertrophy is mediated by membrane receptors, we explored the expression of melatonin membrane receptors (MT1 and MT2) of the C3H10T1/2 cell line. Representative immunofluorescence pictures are presented in Fig. 4A. The mRNA 
levels of hypertrophic genes like COLX, RUNX2, IHH, and PTHrP-R were reduced after luzindol (a blocker of the melatonin receptor) treatment in melatonin-mediated hypertrophic differentiation (Fig. 4B-4E). These data demonstrated that melatonin-mediated hypertrophic differentiation was mediated via membrane receptors.

\section{Melatonin activates WNT-target genes in the hypertrophic differentiation of BMSC-derived chondrocytes}

To elucidate the molecular mechanism underlying melatonin-mediated hypertrophic differentiation, a quantitative real-time polymerase chain reaction (qRT-PCR) array was performed after melatonin treatment for 1,3 , and 5 days with or without hypertrophic inducement. We found that the expression of multiple target genes of the WNT/ $\beta$-catenin signaling pathway was elevated after melatonin treatment (Fig. 5A and 5B), especially in the 5-day treated group. T-cell factor/lymphoid enhancer factor (TCF/LEF), a crucial transcription factor of the WNT/ $\beta$-catenin signaling pathway, was up-regulated at both the mRNA level and protein level when melatonin was added, explaining that melatonin-mediated hypertrophic differentiation might be facilitated through related genes (Fig. 5C and 5D).

\section{Melatonin promotes the nuclear translocation of $\beta$-catenin in the $\mathrm{C} 3 \mathrm{H} 10 \mathrm{~T} 1 / 2$ cell line}

$\beta$-catenin is a crucial protein that translocates from the cytoplasm into the nucleus when WNT signaling is activated. The immunofluorescence pictures of $\beta$-catenin in C3H10T1/2 cells stimulated by melatonin are presented in (Fig. 6A). Fluorescence accumulation was observed in the melatonin group and the CHIR90021 (an agonist of the WNT pathway)-treated group. Western blot revealed that the nuclear $\beta$-catenin level was up-regulated while the cytoplasm $\beta$-catenin level was down-regulated after melatonin stimulation (Fig. 6B and 6D), which could be reversed by XAV-939, an inhibitor of the WNT/ $\beta$-catenin signaling pathway. Gray value analysis also showed a significant difference (Fig. 6C).

\section{Melatonin-mediated hypertrophic differentiation through WNT/ $\beta$-catenin signaling}

The data above revealed that melatonin activated the WNT/ $\beta$-catenin pathway target gene expression and promoted nuclear translocation. However, it is still doubtful whether this change is related to the hypertrophic differentiation of chondrocytes. To verify this connection, the hypertrophic characteristics of the chondrocytes treated with melatonin were examined after the pharmacal regulation of WNT/ $\beta$-catenin signaling. The BMSC-derived chondrocytes were induced to hypertrophic differentiation with melatonin for 14 days. The melatonin-enhanced expression of type $X$ collagen was partially reversed by XAV-939 (Fig. 7A). IOD analysis is showed in Fig. 7B. Gene expression of RUNX2, COL10A1, and IHH was also decreased when XAV-939 was present in the melatonin-induced hypertrophic chondrocytes (Fig. 7E). 


\section{Discussion}

Our previous studies of melatonin-orchestrating BMSC chondrogenesis reported that the hypertrophyrelated genes in the melatonin treatment group were more highly expressed than those in the controls in the later differentiation period [24]. In this study, we identified melatonin as a promoter of MSC-derived chondrocyte hypertrophy differentiation. Our data demonstrated that melatonin could enhance the MSCderived chondrocyte differentiation into hypertrophy via the membranous receptors, followed by the activation of the WNT/ $\beta$-catenin signaling pathway.

Intramembranous and endochondral ossification, two essential processes for bone formation, contribute to skeletal architecture and bone building [26]. Intramembranous ossification is responsible for the rudimentary development of cranial bones and also plays a role in bone fracture healing, where MSCs directly develop into osteoblasts without cartilage participation. Unlike intramembranous bone formation, cartilage acts as a transitional form in EO. EO is responsible for the skeletal development of the trunk and limbs in vertebrates.

In previous studies, melatonin was found to be involved in the cell fate choice of BMSC differentiation into osteoblasts rather than adipocytes [27-29], which emphasized the anti-osteoporosis action of melatonin. Melatonin is also regarded as a bio-activator for bone repair due to its anti-oxygenation ability in the early stage and its angiogenesis-promoting ability in the late stage of bone repair [30, 31].

Studies showed that melatonin can promote the production of the cartilage matrix in porcine articular chondrocytes and up-regulate the chondrocyte hallmark type collagen II rather than the hypertrophic biomarker type collagen $X$ [22]. Our previous study showed that melatonin can enhance the chondrogenesis of human bone marrow mesenchymal stem cells (hBMSCs) partially via membranous receptors [24]. We found that melatonin can up-regulate the expression of the hypertrophy related genes COL10A1 and RUNX2 of the hBMSC-derived chondrocytes in a chondrogenic medium [24]. Melatonin is deemed to have a protective effect due to its resistance against inflammation and oxidization in the maintenance of cartilaginous joints. Guo et al. reported that melatonin could reduce matrix metalloproteinase production via the inhibition of Sirtuin-1-dependent NAMPT and NFAT5 signaling in chondrocytes [32]. Melatonin combined with treadmill exercise may have both preventive and synergistic effects on cartilage degeneration and is more effective in the initial phase.

The hypertrophic chondrocytes are recognized as the greatest contributors to bone growth rate due to the expansion of cell volume in the growth plate. They are also excellent predictors for joint degenerative diseases, such as osteoarthritis, which is an age-related disorder that causes the loss of cartilage in joints. Although hypertrophic chondrocytes in the growth plate and degenerative joint share high similarities in gross morphology, they are not exactly the same. Cooper et al. explained that chondrocytes in the growth plate undergo three phases for hypertrophic differentiation: Phase 1, true hypertrophy, is characterized by dry mass production proportionately increasing with fluid uptake; phase 2, cell swelling, is characterized by fluid uptake increasing proportionately and greater than dry mass production; and phase 3, another true hypertrophy, is controlled by the IGF1 signaling pathway [7]. In contrast to the 
growth plate chondrocytes, articular chondrocytes increase in volume by extracellular matrix degradation and collagen network damage, leading to hypo-osmotic swelling in the initial stage of osteoarthritis [3336].

A previous study mentioned that melatonin can reduce the mRNA levels of hypertrophic markers such as COL10A1 and ALP in the growth plate chondrocytes (GPCs) [37]. Our present data, derived from both human BMSC and $\mathrm{C} 3 \mathrm{H} 10 \mathrm{~T} 1 / 2$ cell analysis, demonstrated that the hallmarks of hypertrophic chondrocytes, such as COL10A1, RUNX2, and ALP, were all upregulated except for matrix metalloproteinase 13(MMP13), a matrix degradation enzyme, after melatonin treatment in the hypertrophic enhancing medium. This means that melatonin contributes to chondrocyte hypertrophy by supporting cellular differentiation instead of promoting the degradation of cartilaginous extracellular matrix. Two opposite functions of melatonin were observed, owing to cellular heterogeneity. First, the GPCs are composed of rest, proliferative, and hypertrophic chondrocytes, which are differentiated cells with a high level of hypertrophy markers; thus, melatonin treatment cannot further enhance the expression of the hypertrophic hallmarks for these mature chondrocytes. Second, the chondrocytes from MSCs, cells with multi-lineage differentiation potentials, showed a favorable ability for hypertrophic differentiation in a micromass culture system [38], and therefore, our results provided completely different information. The IHH/ PTHrP negative feed-back loop acts as a pivotal effector of EO. IHH, located in prehypertrophic chondrocytes, promotes the production of PTHrP in proliferative chondrocytes. PTHrP suppresses the $\mathrm{IHH}$ expression by binding with PTHrP receptors, which are expressed on hypertrophic chondrocyte membranes, leading to an outcome that favors chondrocyte proliferation over hypertrophic differentiation. Our results showed that melatonin enhanced IHH and PTHrP-R expression and suppressed PTHrP in hBMSC-derived chondrocytes. Collectively, our present study indicated that melatonin acts as a vital promoter of EO by regulating chondrocyte hypertrophy during MSC differentiation.

The hypertrophic differentiation of chondrocytes is regulated by many kinds of cellular pathways, among which, the classical WNT pathway has been mentioned by many scholars. The WNT family consists of 19 kinds of proteins, which can be divided into classical and non-classical WNT pathways according to whether their downstream pathways need $\beta$-catenin parameters or not [39-41]. Both classical and nonclassical WNT pathways play an important role in the development of bone and cartilage. Many WNT proteins have been found in the cartilage growth plate [42]. Hartmann et al. found that WNT5b/11 was expressed in pre-hypertrophic chondrocytes in chicken limb buds, while WNT4 was not expressed in hypertrophic chondrocytes [43]. In the same study of chicken cartilage development, Rudnicki also found that the abnormal position of WNT7 leads to limb chondrodysplasia in chickens [44]. Similar studies have shown that abnormalities in WNT5a/5b hinders limb cartilage hypertrophy and differentiation [42, 43]. Interestingly, WNT proteins are not expressed in resting and proliferative chondrocytes, mainly hypertrophic and pre-hypertrophic chondrocytes [43]. These WNT proteins primarily originate from the perichondrium and osteoblasts in the surrounding cancellous bone. In this study, when the chondrocytes derived from stem cells were cultured in 3D and hypertrophy was induced by the addition of thyroxine T3, gene chip analysis showed no significant difference in the expression of WNT5a/5b and WNT4 proteins; 
however, a decrease in the expression of WNT11 and the rare expression of other WNT protein genes were observed. This may be due to the fact that WNT proteins mainly originate from the perichondrium and osteoblasts around the growth plate in vivo but not from chondrocytes.

XAV-939 is an inhibitor of terminal anchor polymerase (tankyrase), which can accelerate the degradation of $\beta$-catenin by stabilizing the axis inhibitor Axin, thus affecting the nuclear transfer of $\beta$-catenin and regulating the transcription of target genes downstream of the ganglion [45]. In this study, it was found that the hypertrophic effect of melatonin on cartilage was inhibited by the addition of XAV-939. Immunohistochemistry of the melatonin + XAV939 group showed that the staining degree of type X collagen was lighter, and the staining range was significantly smaller than that in the melatonin group. This suggests that melatonin can promote the hypertrophy of MSC-derived chondrocytes by regulating the nuclear transfer of $\beta$-catenin. The western blotting results further showed that after the addition of melatonin, the expression of $\beta$-catenin in the nucleus increased significantly and cytoplasmic $\beta$-catenin decreased significantly, which could be reversed by XAV939, suggesting that melatonin can accelerate the nuclear transfer of $\beta$-catenin.

To summarize, the molecular mechanism by which melatonin promotes the hypertrophy and differentiation of MSC-derived chondrocytes involves activating the WNT/ $\beta$-catenin signal pathway and accelerating the nuclear transfer of $\beta$-catenin.

\section{Conclusions}

This study added evidence that melatonin is a regulator of MSC differentiation and bone development. We hope that our studies can further facilitate the move from the investigation of the mechanism of action of melatonin to the clinical application of melatonin in the treatment of skeletal developmental diseases.

\section{Abbreviations}

MSCs: Mesenchymal stem cells

COL10A1: Type X collagen

ALP: Alkaline phosphatase

RUNX2: Runt-related transcription factor 2

IHH: Indian hedgehog

PTHrP-R: Parathyroid hormone-related protein receptor

PTHrP: Parathyroid hormone-related protein 
EO: Endochondral ossification

TCF: T cell-specific factor

LEF: Lymphoid enhancer binding protein

BMSCs: Bone marrow mesenchymal stem cells

DMEM: Dulbecco's modified Eagle's medium

FBS: Fetal bovine serum

PCRs: Polymerase chain reactions

TGF- $\beta 3$ : Transforming growth factor- $\beta 3$

COLX: Collagen type X

GAPDH: Glyceraldehyde-3-phosphate dehydrogenase

Col-II: Type II collagen

Col-X: Type X collagen

IOD: Integral optical density

qRT-PCR: Quantitative real-time polymerase chain reaction

TCF/LEF: T-cell factor/lymphoid enhancer factor

GPCs: Growth plate chondrocytes

Hbmsc: Human bone marrow mesenchymal stem cells

MMP13: Matrix metalloproteinase 13

\section{Declarations}

\section{Ethics approval and consent to participate}

The study design was approved by the Ethics Committee of The Third Affiliated Hospital of Sun Yat-sen University, Guangzhou, China. All included volunteers were informed about the nature of the study and gave their written informed consent.

\section{Consent for publication}

All volunteers signed a consent form for their data to be used for research or publication. 
Availability of data and materials

The data sets used and analyzed during the current study are available from the corresponding author upon reasonable request.

\section{Competing interests}

The authors declare that they have no competing interests.

\section{Funding}

This study was supported by National Natural Science Foundation of China (No. 81972111, No. 81772398 and No. 81301524), and the Fundamental Research Funds for the Central Universities (No. 15ykpy23).

\section{Authors' contributions}

Conception and design: L.M.R., L.M.Z., X.W.; data analysis and interpretation, and manuscript writing: X.W., T.W.H.; provision of study materials and MSCs quality control: P.G.X., M.P.; collection and assembly of data: X.W., T.W.H., L.H., B.Y., Z.Y.L.; obtaining of funding: L.M.R., L.M.Z.; drafting of the article:L.M.R., L.M.Z., X.W..The authors read and approved the final manuscript.

\section{Acknowledgments}

We are grateful to all the clinical investigators and volunteers included in the study.

\section{References}

1. Kronenberg HM: Developmental regulation of the growth plate. Nature 2003, 423(6937):332-336.

2. White A, Wallis G: Endochondral ossification: a delicate balance between growth and mineralisation. Curr Biol 2001, 11(15):R589-591.

3. Mackie EJ, Tatarczuch L, Mirams M: The skeleton: a multi-functional complex organ: the growth plate chondrocyte and endochondral ossification. J Endocrinol 2011, 211(2):109-121.

4. Sun MM, Beier F: Chondrocyte hypertrophy in skeletal development, growth, and disease. Birth Defects Res C Embryo Today 2014, 102(1):74-82.

5. Long F, Ornitz DM: Development of the endochondral skeleton. Cold Spring Harb Perspect Biol 2013, 5(1):a008334.

6. Kuhn JL, DeLacey JH, Leenellett EE: Relationship between bone growth rate and hypertrophic chondrocyte volume in New Zealand white rabbits of varying ages. J Orthop Res 1996, 14(5):706711.

7. Cooper KL, Oh S, Sung Y, Dasari RR, Kirschner MW, Tabin CJ: Multiple phases of chondrocyte enlargement underlie differences in skeletal proportions. Nature 2013, 495(7441):375-378. 
8. Zhong L, Huang X, Karperien M, Post JN: The Regulatory Role of Signaling Crosstalk in Hypertrophy of MSCs and Human Articular Chondrocytes. Int J Mol Sci 2015, 16(8):19225-19247.

9. Guo X, Mak KK, Taketo MM, Yang Y: The Wnt/beta-catenin pathway interacts differentially with PTHrP signaling to control chondrocyte hypertrophy and final maturation. PLoS One 2009, 4(6):e6067.

10. Yano F, Saito T, Ogata N, Yamazawa T, lino M, Chung UI, Kawaguchi H: beta-catenin regulates parathyroid hormone/parathyroid hormone-related protein receptor signals and chondrocyte hypertrophy through binding to the intracellular C-terminal region of the receptor. Arthritis Rheum 2013, 65(2):429-435.

11. Yano F, Kugimiya F, Ohba S, Ikeda T, Chikuda H, Ogasawara T, Ogata N, Takato T, Nakamura K, Kawaguchi $\mathrm{H}$ et al: The canonical Wnt signaling pathway promotes chondrocyte differentiation in a Sox9-dependent manner. Biochem Biophys Res Commun 2005, 333(4):1300-1308.

12. Dong YF, Soung do Y, Schwarz EM, O'Keefe RJ, Drissi H: Wnt induction of chondrocyte hypertrophy through the Runx2 transcription factor. J Cell Physiol 2006, 208(1):77-86.

13. Claustrat B, Leston J: Melatonin: Physiological effects in humans. Neurochirurgie 2015, 61(2-3):7784.

14. Johnston JD, Skene DJ: 60 YEARS OF NEUROENDOCRINOLOGY: Regulation of mammalian neuroendocrine physiology and rhythms by melatonin. J Endocrinol 2015, 226(2):T187-198.

15. Arendt J: Melatonin and human rhythms. Chronobiol Int 2006, 23(1-2):21-37.

16. Vinther $\mathrm{AG}$, Claesson $\mathrm{MH}$ : [The influence of melatonin on the immune system and cancer]. Ugeskr Laeger 2015, 177(21):V10140568.

17. Singh AK, Ghosh S, Basu P, Haldar C: Daily variation in melatonin level, antioxidant activity and general immune response of peripheral blood mononuclear cells and lymphoid tissues of Indian goat Capra hircus during summer and winter. Indian J Exp Biol 2014, 52(5):467-477.

18. Zhou L, Chen X, Liu T, Gong Y, Chen S, Pan G, Cui W, Luo ZP, Pei M, Yang H et al: Melatonin reverses $\mathrm{H} 2 \mathrm{O} 2$-induced premature senescence in mesenchymal stem cells via the SIRT1-dependent pathway. J Pineal Res 2015, 59(2):190-205.

19. Parisotto EB, Vidal V, Garcia-Cerro S, Lantigua S, Wilhelm Filho D, Sanchez-Barcelo EJ, Martinez-Cue C, Rueda N: Chronic Melatonin Administration Reduced Oxidative Damage and Cellular Senescence in the Hippocampus of a Mouse Model of Down Syndrome. Neurochem Res 2016, 41(11):29042913.

20. Sharan K, Lewis K, Furukawa T, Yadav VK: Regulation of bone mass through pineal-derived melatonin-MT2 receptor pathway. J Pineal Res 2017, 63(2).

21. van der Pol CW, van Roovert-Reijrink IAM, Maatjens CM, Gussekloo SWS, Kranenbarg S, Wijnen J, Pieters RPM, Schipper H, Kemp B, van den Brand H: Light-dark rhythms during incubation of broiler chicken embryos and their effects on embryonic and post hatch leg bone development. PLoS One 2019, 14(1):e0210886. 
22. Pei M, He F, Wei L, Rawson A: Melatonin enhances cartilage matrix synthesis by porcine articular chondrocytes. J Pineal Res 2009, 46(2):181-187.

23. Zhong ZM, Li T, Xu ZX, Meng TT, Zeng JH, Zheng S, Ye WB, Wu Q, Chen JT: Effect of melatonin on the proliferation and differentiation of chondrocytes from rat vertebral body growth plate in vitro. Int J Med Sci 2013, 10(10):1392-1398.

24. Gao W, Lin M, Liang A, Zhang L, Chen C, Liang G, Xu C, Peng Y, Chen C, Huang D et al: Melatonin enhances chondrogenic differentiation of human mesenchymal stem cells. J Pineal Res 2014, 56(1):62-70.

25. Zhang L, Su P, Xu C, Yang J, Yu W, Huang D: Chondrogenic differentiation of human mesenchymal stem cells: a comparison between micromass and pellet culture systems. Biotechnol Lett 2010, 32(9):1339-1346.

26. Berendsen AD, Olsen BR: Bone development. Bone 2015, 80:14-18.

27. Zhang L, Su P, Xu C, Chen C, Liang A, Du K, Peng Y, Huang D: Melatonin inhibits adipogenesis and enhances osteogenesis of human mesenchymal stem cells by suppressing PPARgamma expression and enhancing Runx2 expression. J Pineal Res 2010, 49(4):364-372.

28. Radio NM, Doctor JS, Witt-Enderby PA: Melatonin enhances alkaline phosphatase activity in differentiating human adult mesenchymal stem cells grown in osteogenic medium via MT2 melatonin receptors and the MEK/ERK (1/2) signaling cascade. J Pineal Res 2006, 40(4):332-342.

29. Han Y, Kim YM, Kim HS, Lee KY: Melatonin promotes osteoblast differentiation by regulating Osterix protein stability and expression. Sci Rep 2017, 7(1):5716.

30. Calvo-Guirado JL, Ramirez-Fernandez MP, Gomez-Moreno G, Mate-Sanchez JE, Delgado-Ruiz R, Guardia J, Lopez-Mari L, Barone A, Ortiz-Ruiz AJ, Martinez-Gonzalez JM et al: Melatonin stimulates the growth of new bone around implants in the tibia of rabbits. J Pineal Res 2010, 49(4):356-363.

31. Halici M, Oner M, Guney A, Canoz O, Narin F, Halici C: Melatonin promotes fracture healing in the rat model. Eklem Hastalik Cerrahisi 2010, 21(3):172-177.

32. Guo JY, Li F, Wen YB, Cui HX, Guo ML, Zhang L, Zhang YF, Guo YJ, Guo YX: Melatonin inhibits Sirt1dependent NAMPT and NFAT5 signaling in chondrocytes to attenuate osteoarthritis. Oncotarget 2017, 8(34):55967-55983.

33. McArthur SD, Gardner DL: Articular cartilage fibrillation and permeability to Light Green SF dye. A method for the detection of pre-microscopic disease? J Bone Joint Surg Br 1992, 74(5):668-672.

34. Wang Z, Irianto J, Kazun S, Wang W, Knight MM: The rate of hypo-osmotic challenge influences regulatory volume decrease (RVD) and mechanical properties of articular chondrocytes. Osteoarthritis Cartilage 2015, 23(2):289-299.

35. Venn M, Maroudas A: Chemical composition and swelling of normal and osteoarthrotic femoral head cartilage. I. Chemical composition. Ann Rheum Dis 1977, 36(2):121-129.

36. Watson PJ, Carpenter TA, Hall LD, Tyler JA: Cartilage swelling and loss in a spontaneous model of osteoarthritis visualized by magnetic resonance imaging. Osteoarthritis Cartilage 1996, 4(3):197-207. 
37. Wang WW, Man GC, Wong JH, Ng TB, Lee KM, Ng BK, Yeung HY, Qiu Y, Cheng JC: Abnormal response of the proliferation and differentiation of growth plate chondrocytes to melatonin in adolescent idiopathic scoliosis. Int J Mol Sci 2014, 15(9):17100-17114.

38. Mueller MB, Tuan RS: Functional characterization of hypertrophy in chondrogenesis of human mesenchymal stem cells. Arthritis Rheum 2008, 58(5):1377-1388.

39. Nusse R: Wnt signaling in disease and in development. Cell Res 2005, 15(1):28-32.

40. Nusse R, Clevers H: Wnt/beta-Catenin Signaling, Disease, and Emerging Therapeutic Modalities. Cell 2017, 169(6):985-999.

41. Miller JR, Hocking AM, Brown JD, Moon RT: Mechanism and function of signal transduction by the Wnt/beta-catenin and Wnt/Ca2+ pathways. Oncogene 1999, 18(55):7860-7872.

42. Yang Y, Topol L, Lee H, Wu J: Wnt5a and Wnt5b exhibit distinct activities in coordinating chondrocyte proliferation and differentiation. Development 2003, 130(5):1003-1015.

43. Hartmann C, Tabin CJ: Dual roles of Wnt signaling during chondrogenesis in the chicken limb. Development 2000, 127(14):3141-3159.

44. Rudnicki JA, Brown AM: Inhibition of chondrogenesis by Wnt gene expression in vivo and in vitro. Dev Biol 1997, 185(1):104-118.

45. Huang SM, Mishina YM, Liu S, Cheung A, Stegmeier F, Michaud GA, Charlat O, Wiellette E, Zhang Y, Wiessner $S$ et al: Tankyrase inhibition stabilizes axin and antagonizes Wnt signalling. Nature 2009, 461(7264):614-620.

\section{Figures}


A
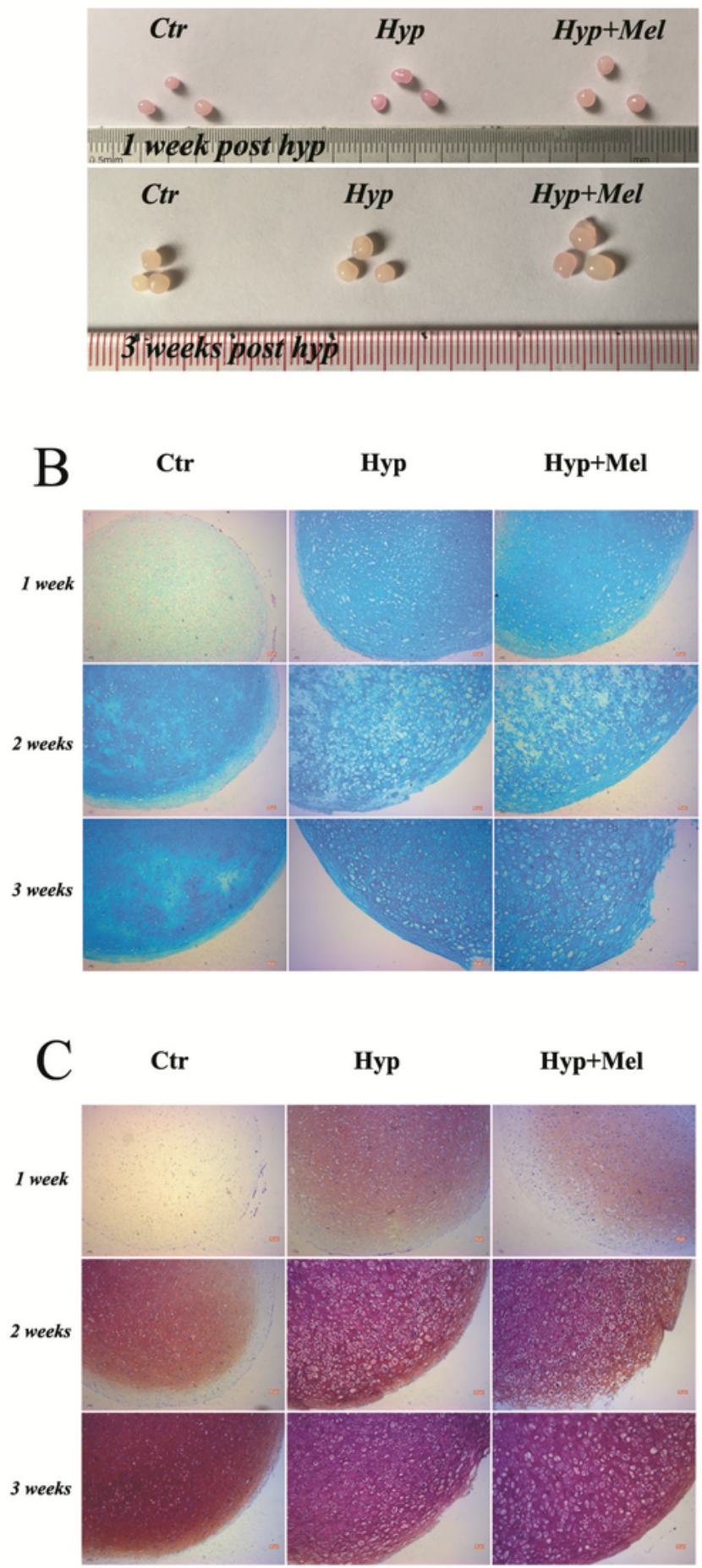

$\mathrm{D}$

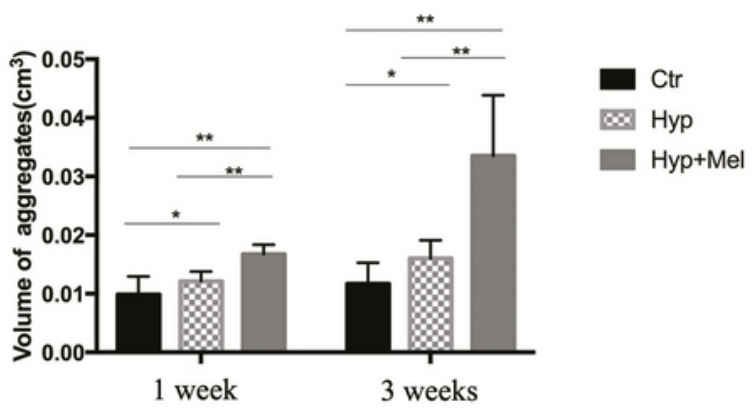

$\mathrm{E}$

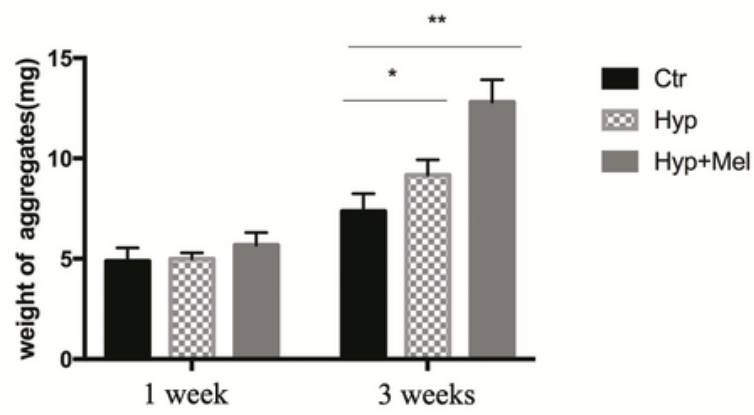

$\mathrm{F}$

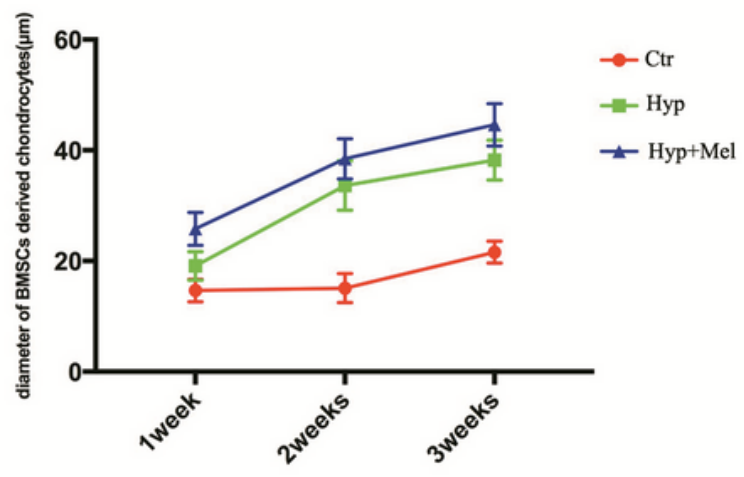

$\mathrm{G}$

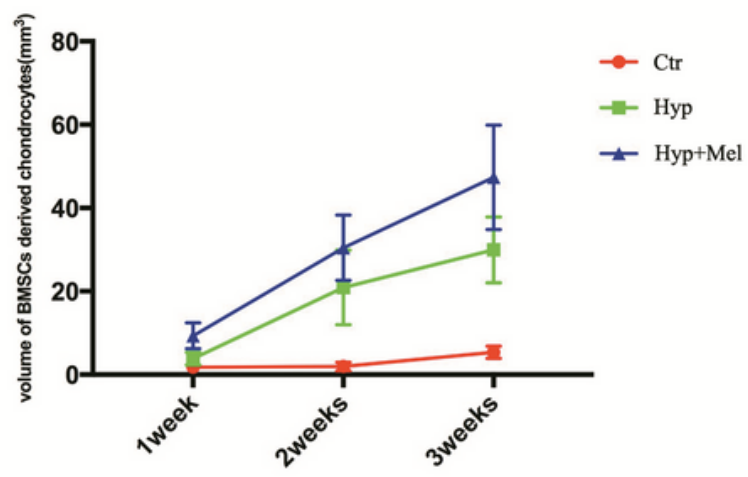

Figure 1

Effect of melatonin on the hypertrophic differentiation of MSC-derived chondrocytes. Cells were seeded in 24-well plates via high-density micro-mass culture and induced along chondrogenic difffferentiation in chondrogenic medium for 2 weeks, then induced hypertrophic differentiation in hypertrophic medium containing $1 \mathrm{nM}$ triiodothyronine with or without 100nM melatonin. \A.morphologic characteristics of aggregates post hypertrophic differentiation 1 week , 2weeks and 3 weeks; B.alcian blue staining for post 
hypertrophic differentiation 1 week, 2 weeks and 3 weeks, scale bar $=200 \mu \mathrm{m}$; C.toluidine blue staining for post hypertrophy differentiation 1 week , 2weeks, 3weeks, scale bar $=200 \mu \mathrm{m}$; D.volume of aggregates;

E.weight of aggregates ; $E$. diameter of chondrocyte; F.volume of chondrocyte $\triangle V$ olume $=4 / 3 \pi R 3, R=1 / 2$ diameter $\rrbracket .{ }^{*} P<0.05,{ }^{* *} P<0.01$.

A

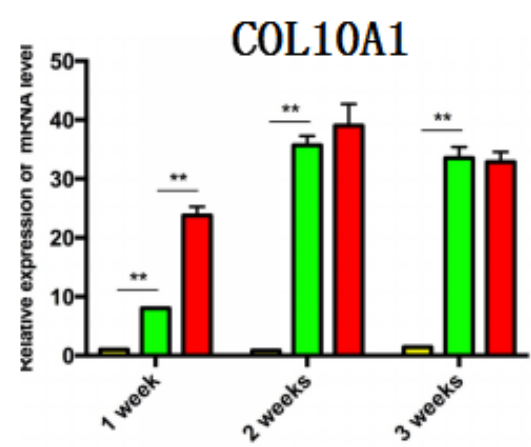

C

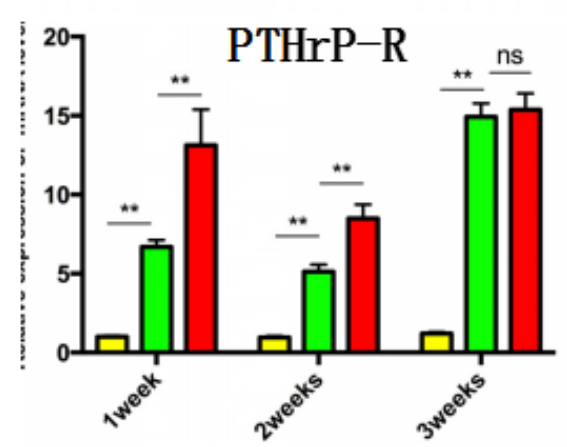

$E$

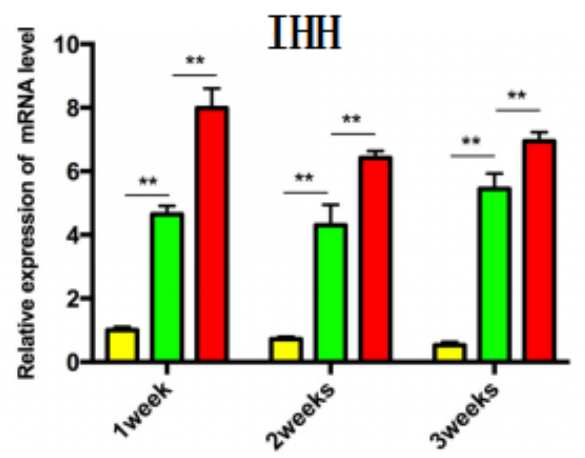

G

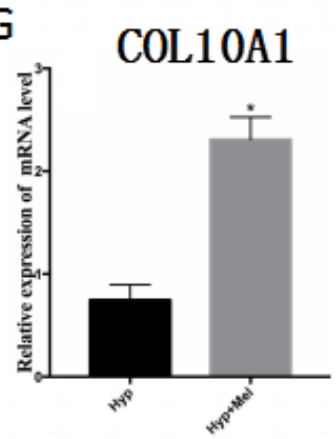

H RUNX2

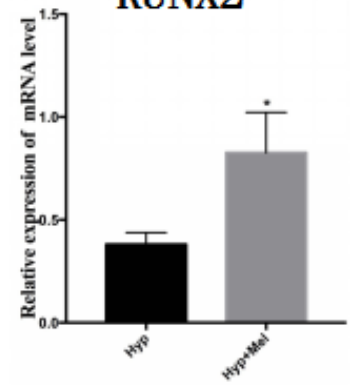

B

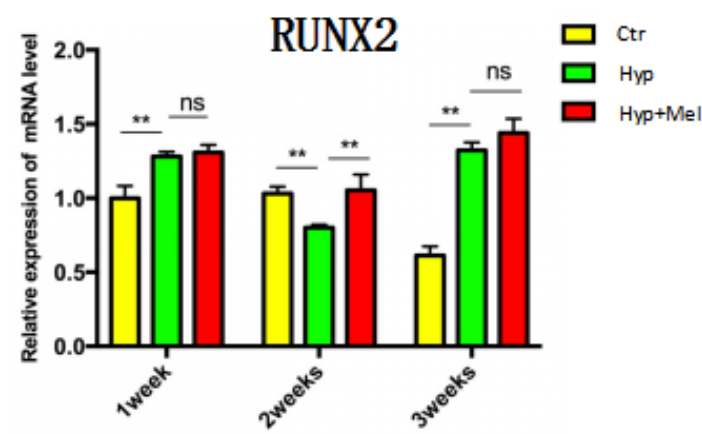

D

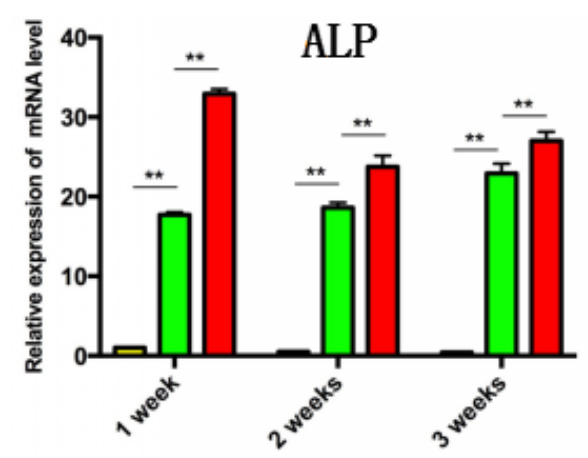

$\mathrm{F}$
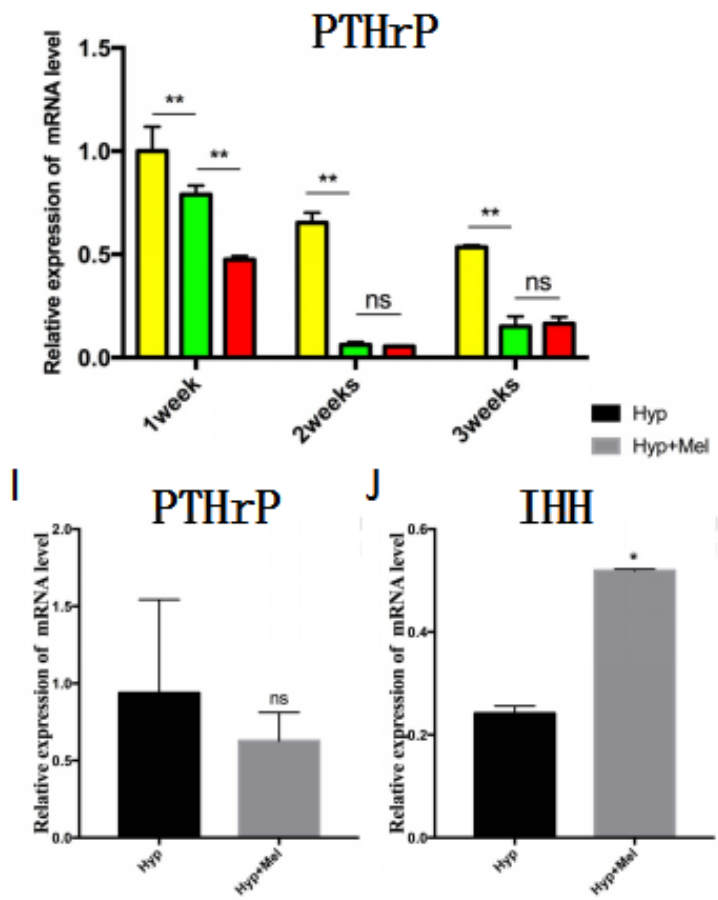

Figure 2 
The effect of melatonin on the expression of genes involved in chondrocyte hypertrophic differentiation. Cells were seeded in 24-well plates via high-density micro-mass culture and induced along chondrogenic difffferentiation in chondrogenic medium for 2 weeks, then induced hypertrophic differentiation in hypertrophic medium containing $1 \mathrm{nM}$ triiodothyronine with or without 100nM melatonin. C3H10T1/2 cells were seeded in 24-well plates induced along chondrogenic difffferentiation in chondrogenic medium for 2 weeks, then induced hypertrophic differentiation in hypertrophic medium containing $1 \mathrm{nM}$ triiodothyronine with or without melatonin for 1 week. The mRNA expression of collagen type $X$ (COL10A1) (A), runt-related transcription factor 2 (RUNX2) (B), parathyroid hormone-related protein receptor (PTHrP-R) (C), alkaline phosphatase (ALP) (D), indian hedgehog $(I H H)(E)$, parathyroid hormonerelated protein (PTHrP) (F) in the MSC-derived chondrocytes, and the mRNA expression of collagen type $X$ (COL10A1) $(G)$, runt-related transcription factor $2(R U N X 2)(H)$, parathyroid hormone-related protein $(\mathrm{PTHrP})(\mathrm{I})$ and indian hedgehog $(\mathrm{IHH})(\mathrm{J})$ in the $\mathrm{C} 3 \mathrm{H} 10 \mathrm{~T} 1 / 2$-derived chondrocytes was measured by quantitative real-time PCR.The relative expression levels of each gene was calculated by $2-\triangle \triangle \mathrm{Ct}$ method using normalization to GAPDH, respectively. ${ }^{*} \mathrm{P}<0.05$. 
A

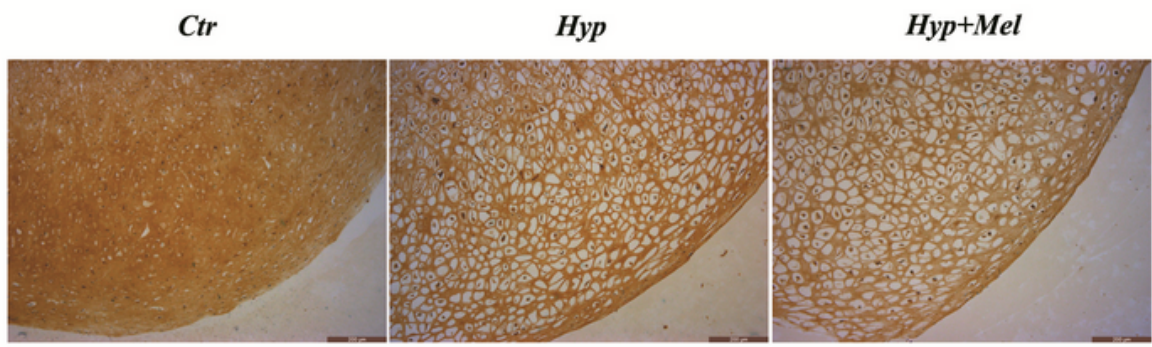

B

Col-П

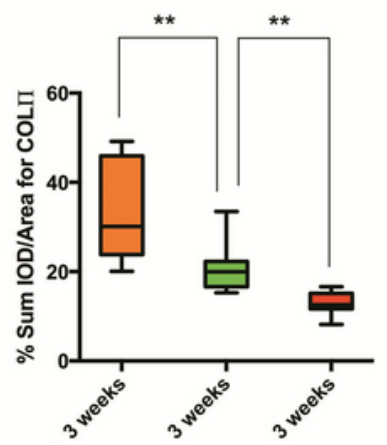

C $\quad$ Col- $\Pi$

$\mathrm{D}$
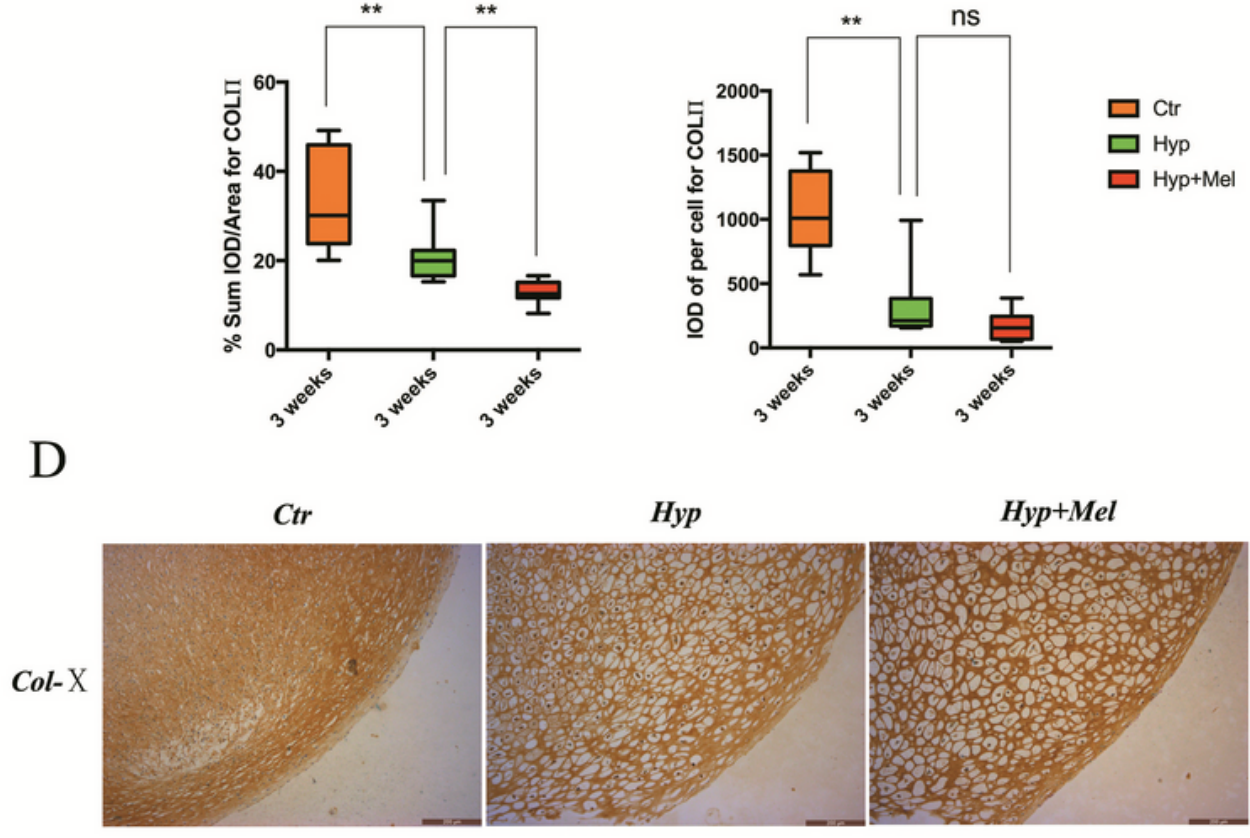

$\mathrm{E}$

Col-X

F Col-X
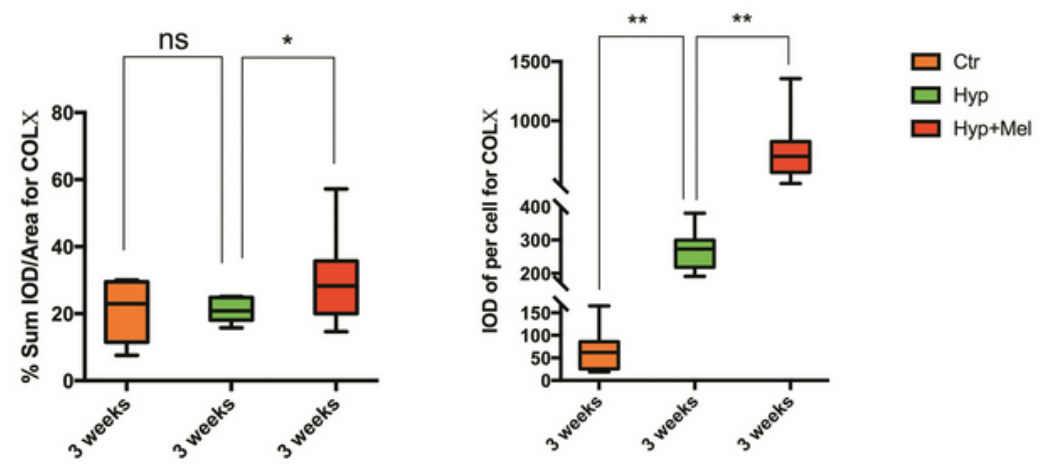

\section{Figure 3}

The effect of melatonin on the expression of bio-markers involved in hypertrophy. Cells were seeded in 24-well plates via high-density micro-mass culture and induced along chondrogenic difffferentiation in chondrogenic medium for 2 weeks, then induced hypertrophic differentiation in hypertrophic medium containing $1 \mathrm{nM}$ triiodothyronine with or without $100 \mathrm{nM}$ melatonin. Immunohistochemical staining was used for aggregates after hypertrophy differentiation 3 weeks (A.type II collagen (Col-II) staining, scale 
bar $=200 \mu \mathrm{m}$; B. Gray value of induced cartilage tissues for type II collagen (Col-II) staining ; C.gray value of induced per chondrocyte for type II collagen (Col-II) staining; D. type X collagen (Col-X) staining, scale bar $=200 \mu \mathrm{m}$; E.gray value of induced per chondrocyte for type $X$ collagen (Col-X) staining; F.Gray value of induced per chondrocyte for type $X$ collagen $($ Col- $X)$ staining. ${ }^{*} P<0.05,{ }^{*} P<0.01$.

A

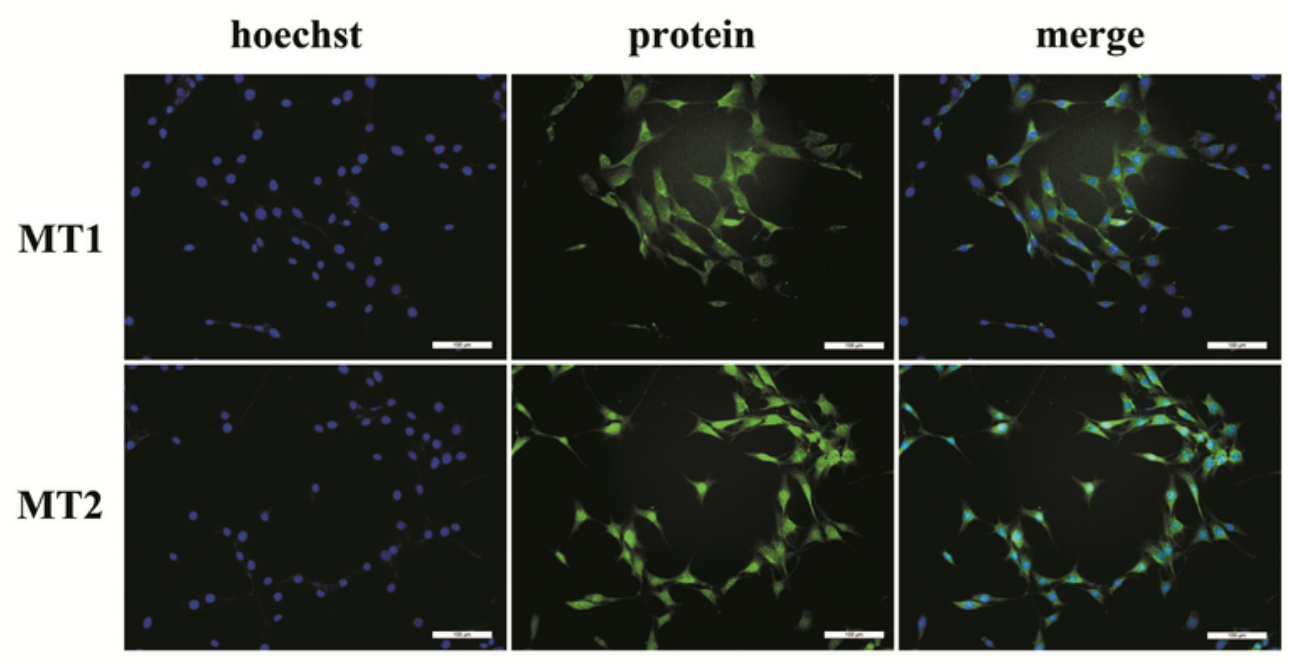

B

$\mathrm{C}$
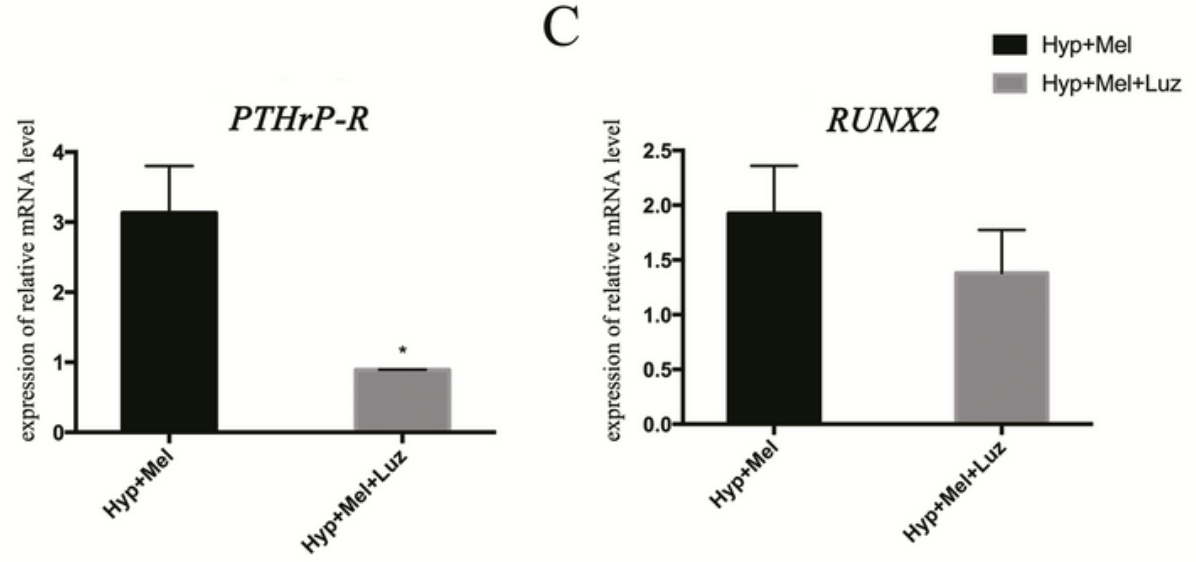

$\mathrm{D}$

$\mathrm{E}$
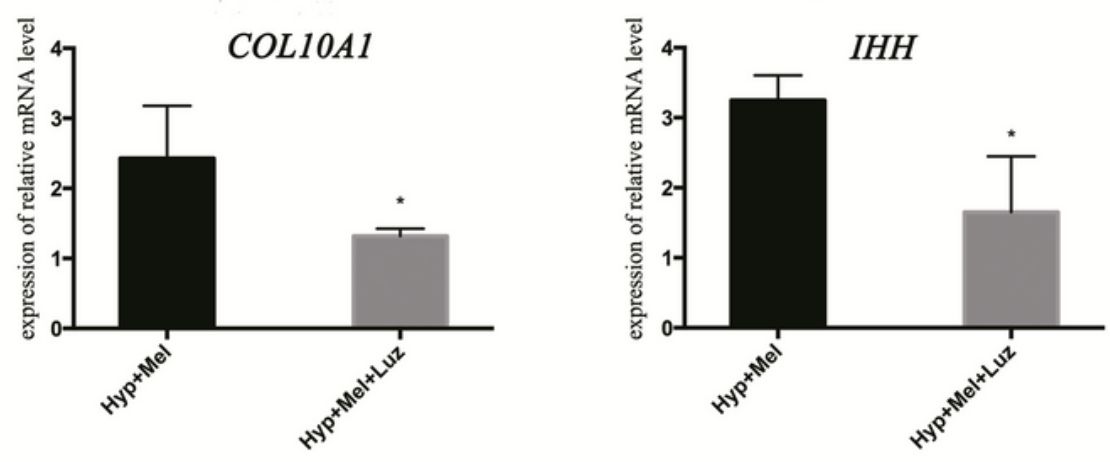

Figure 4 
Melatonin membrane receptor inhibitor blocks melatonin-mediated hypertrophic acceleration. C3H10T1/2 cells were seeded in 24-well plates induced along chondrogenic difffferentiation in chondrogenic medium for 2 weeks, then induced hypertrophic differentiation in hypertrophic medium containing $1 \mathrm{nM}$ triiodothyronine with or without $100 \mathrm{nM}$ melatonin and $5 \mu \mathrm{M}$ luzindol for 1 week. A. melatonin membranaceous receptor (MT1/2) expression in C3H10T1/2 cells; The mRNA expression of the parathyroid hormone-related protein receptor (PTHrP-R) (B), runt-related transcription factor 2 (RUNX2) (C), collagen type X (COL10A1) (D), indian hedgehog $(\mathrm{IHH})(\mathrm{E})$ in C3H10T1/2 -derived chondrocytes was measured by quantitative real-time PCR.The relative expression levels of each gene was calculated by 2$\triangle \triangle \mathrm{Ct}$ method using normalization to GAPDH, respectively. ${ }^{*} \mathrm{P}<0.05$.

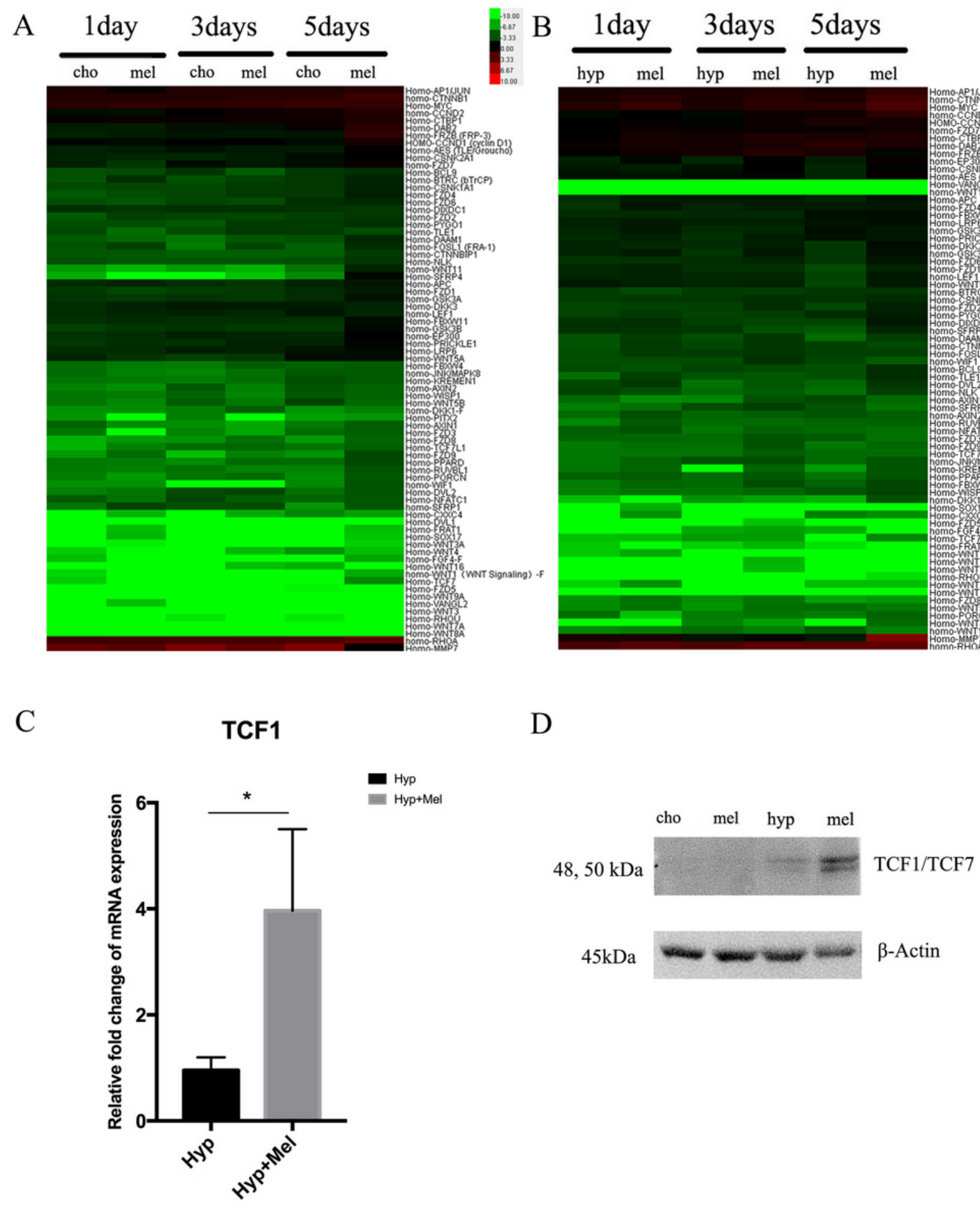




\section{Figure 5}

The effect of melatonin on the expression of downstream genes of WNT/ $\beta$-catenin signaling pathway. MSCs were seeded in 24-well plates via high-density micro-mass culture and induced along chondrogenic diffferentiation in chondrogenic medium for 2 weeks,then induced hypertrophic differentiation in hypertrophic medium containing $1 \mathrm{nM}$ triiodothyronine with or without $100 \mathrm{nM}$ melatonin. A.the expression of downstream genes of WNT/ $\beta$-catenin signaling pathway of MSCs-derived cartilage with or without $100 \mathrm{nM}$ melatonin treatment for 1 day, 3days, 5 days. B.the expression of downstream genes of WNT/ $\beta$-catenin signaling pathway with or without $100 \mathrm{nM}$ melatonin treatment for 1 day, 3 days, 5 days; B.the expression of downstream genes of WNT/ $\beta$-catenin signaling pathway of MSCs-derived cartilage post hypertrophic differentiation with or without $100 \mathrm{nM}$ melatonin treatment for 1 day, 3 days, 5 days; C.The mRNA expression of TCF1 in the MSC-derived cartilage post hypertrophic differentiation was measured by quantitative real-time PCR.The relative expression levels of each gene was calculated by 2$\triangle \triangle \mathrm{Ct}$ method using normalization to GAPDH, respectively; D.the protein expression of TCF1/TCF7 in the MSC-derived chondrocytes. ${ }^{*} \mathrm{P}<0.05$.

A

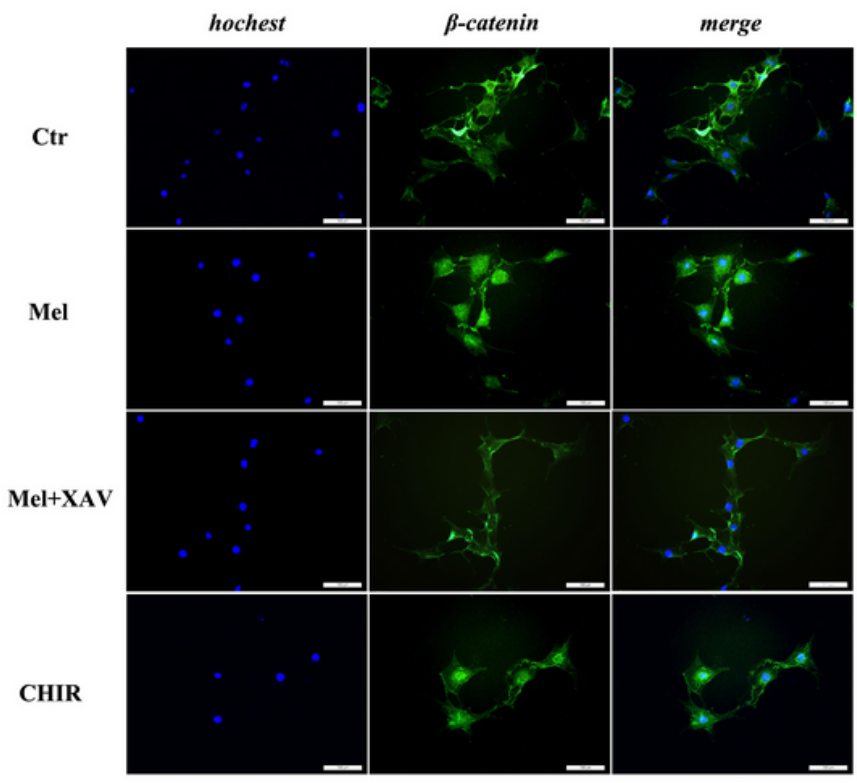

B

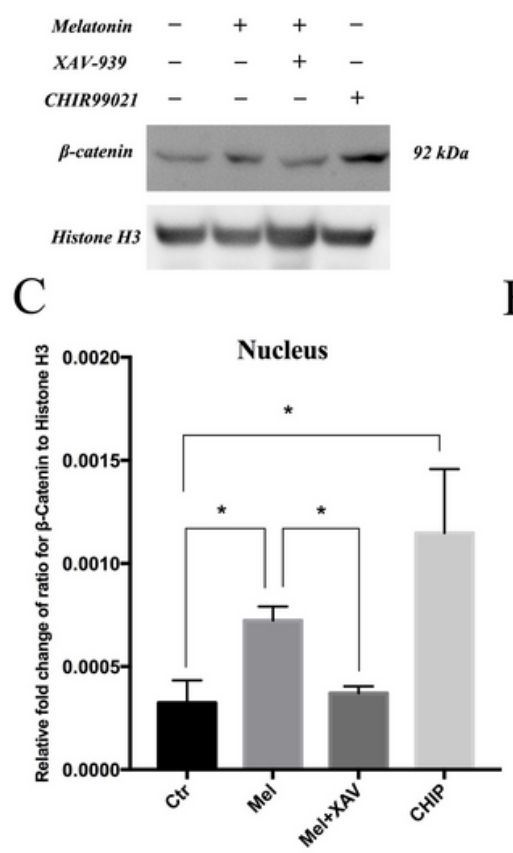

$\mathrm{D}$

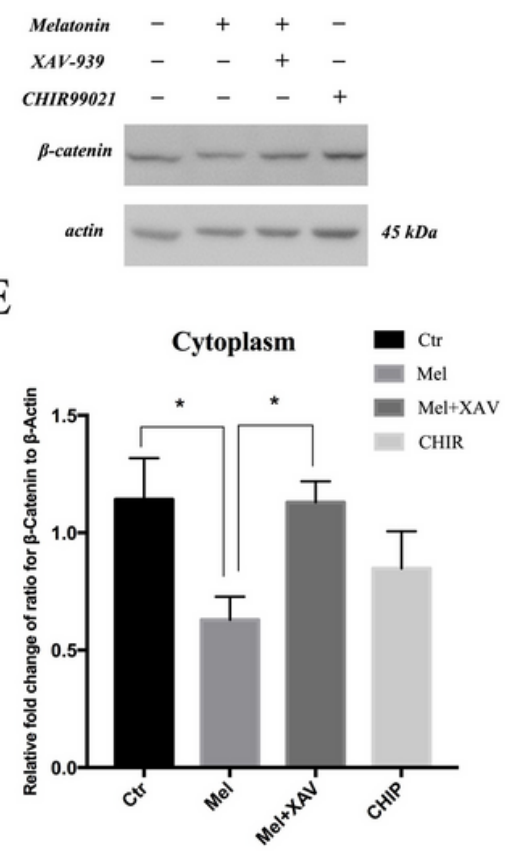

\section{Figure 6}

Melatonin promotes the nuclear translocation of $\beta$-catenin in the $\mathrm{C} 3 \mathrm{H} 10 \mathrm{~T} 1 / 2$ cell line. A. immunofluorescence staining of $\beta$-catenin on C3H10T1/2 cells with or without $100 \mathrm{nM}$ melatonin and blocking-up melatonin membranaceous receptor with $5 \mu \mathrm{M}$ luzindol for 6 hours in 2D culture and respectively. scale bar $=100 \mu \mathrm{m} ; \mathrm{B}$. $\beta$-catenin's protein level in nuclear; $\mathrm{C}$.gray value analysis of $\beta$-catenin's protein level in nuclear; D. $\beta$-catenin's protein level in plasma; E.gray value analysis of $\beta$-catenin's protein level in plasma. 
A

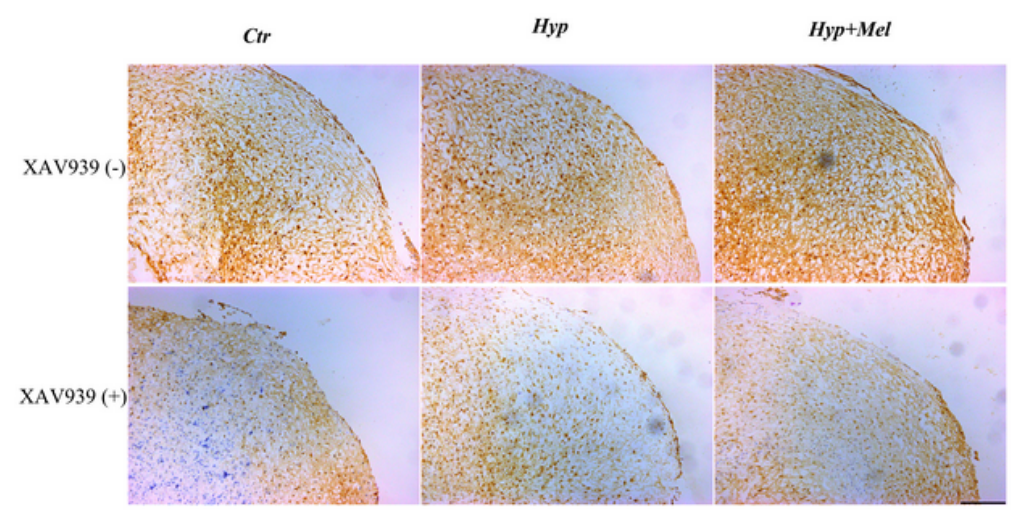

$\mathrm{C}$

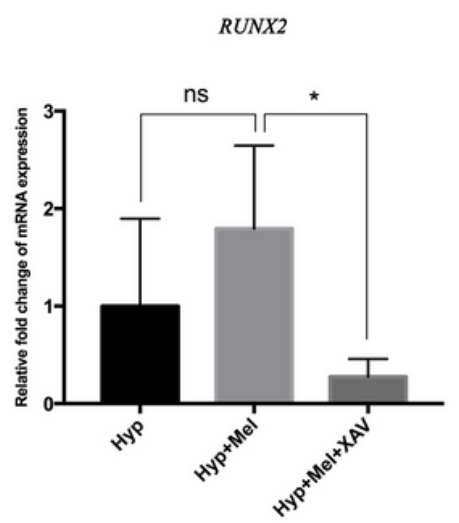

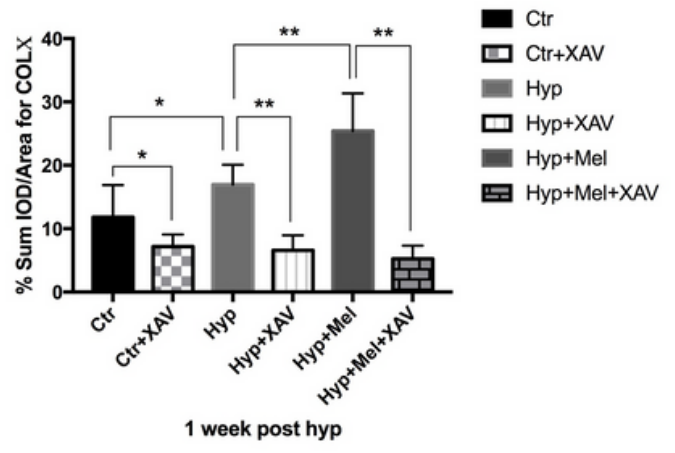

$\mathrm{E}$

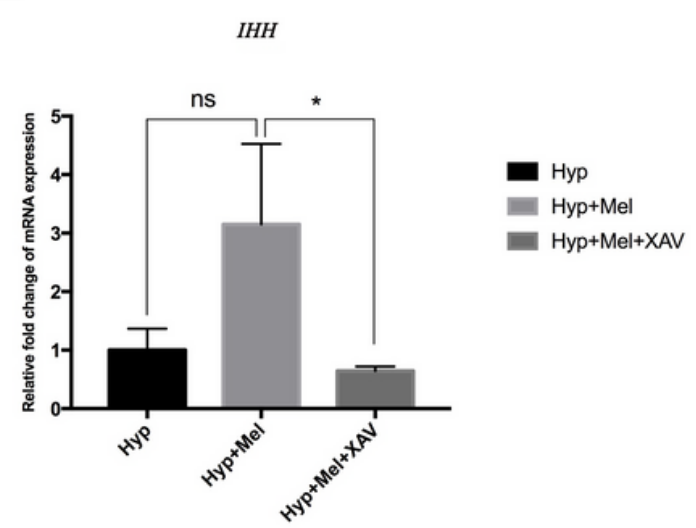

\section{Figure 7}

WNT/ $\beta$-catenin signaling pathway inhibitor blocks melatonin-mediated hypertrophic enhancing. Cells were seeded in 24-well plates via high-density micro-mass culture and induced along chondrogenic difffferentiation in chondrogenic medium for 2 weeks,then induced hypertrophic differentiation in hypertrophic medium containing $1 \mathrm{nM}$ triiodothyronine with or without $100 \mathrm{nM}$ melatonin and WNT/ $\beta$ catenin signaling pathway inhibitor XAV-939 for 1 week. A.Col-X staining for MSC-derived cartilage, scale bar $=200 \mu \mathrm{m}$. B.gray value analysis of Col-X staining of the MSC-derived cartilage; C.the mRNA expression of runt-related transcription factor 2 (RUNX2) (C), collagen type X (COL10A1) (D), indian hedgehog (IHH) $(\mathrm{E})$ in the $\mathrm{C} 3 \mathrm{H} 10 \mathrm{~T} 1 / 2$-derived chondrocytes was measured by quantitative real-time PCR.The relative expression levels of each gene was calculated by $2-\triangle \triangle \mathrm{Ct}$ method using normalization to GAPDH, respectively. ${ }^{*} P<0.05,{ }^{\star} * \mathrm{P}<0.01$. 